\title{
MOG-IgG associated optic neuritis is not multiple sclerosis
}

\author{
Neurite óptica associada ao MOG-IgG não é esclerose múltipla \\ Bruna Klein da Costa ${ }^{1,2, *}$, Giordani Rodrigues dos Passos ${ }^{1,2, *}$, Jefferson Becker ${ }^{1,2}$, Douglas Kazutoshi Sato ${ }^{1,2}$
}

\begin{abstract}
Autoantibodies against myelin oligodendrocyte glycoprotein (MOG-IgG) have been reported in patients with inflammatory central nervous system disorders including isolated optic neuritis (ON). We compared our MOG-IgG ON patients with multiple sclerosis (MS) patients presenting with ON. Methods and results: Among the total of 38 patients with optic neuropathies, six patients with isolated ON were MOG-IgG positive and eight patients with ON fulfilled the diagnostic criteria for MS. All MS patients were negative for MOG-IgG using a cell-based assay. When compared with the MS group, the MOG-IgG patients were older (mean 47 years), more frequently male (ratio 2:1) and had a higher frequency of bilateral and/or recurrent ON. The brain magnetic resonance imaging of all MOG-IgG positive patients was normal or had only unspecific white matter T2 lesions. Conclusion: These findings suggest that MOG-IgG is a biomarker of an inflammatory demyelinating CNS disease distinct from MS.
\end{abstract}

Keywords: optic neuritis; multiple sclerosis; myelin oligodendrocyte glycoprotein;, autoantibodies; demyelinating diseases.

\section{RESUMO}

Autoanticorpos contra a glicoproteína da mielina do oligodendrócito (MOG-lgG) têm sido descritos em pacientes com neurite óptica (NO) isolada, entre outras doenças inflamatórias do sistema nervoso central. Comparamos os nossos pacientes com NO MOG-IgG positivos com pacientes com NO associada a esclerose múltipla (EM). Materias e métodos: De um total de 38 pacientes com neuropatia óptica, seis foram MOG-IgG positivos e oito preencheram critérios diagnósticos para EM. Todos os pacientes com EM foram negativos para MOG-IgG (ensaio baseado em células). Quando comparados ao grupo com EM, os pacientes MOG-IgG positivos apresentam idade mais avançada (mediana de 47 anos) e tiveram uma frequência maior de NO bilateral e/ou recorrente. Houve predomínio masculino (relação 2:1). A ressonância magnética de encéfalo de todos os pacientes MOG-IgG positivos foi normal ou demonstrou apenas lesões inespecíficas em T2. Conclusão: Nossos achados sugerem que o MOG-IgG é um biomarcador de doença desmielinizante diferente da EM.

Palavras-chave: neurite óptica; esclerose múltipla; glicoproteína mielina- oligodendrócito; autoanticorpos; doenças desmielinizantes

The idiopathic acquired inflammatory central nervous system (CNS) disorders are a heterogenous group of autoimmune conditions caused by inflammation, myelin loss ${ }^{1}$, axonal lesion and neurodegeneration'. The most frequent and extensively studied is multiple sclerosis (MS) and its diagnosis is based on clinical and magnectic resonance imaging (MRI) characteristics. Multiple sclerosis is only diagnosed after the exclusion of other etiologies given that it still lacks a reliable biomarker. Since the identification of the anti-aquaporin-4 antibody (AQP4-IgG) and its strong association with neuromyelitis optica spectrum disorders (NMOSD) $)^{3}$, the interest has grown in the development of new laboratory biomarkers that could be used in the differential diagnosis of CNS demyelinating conditions.

Several other CNS antigens have been evaluated as potential targets in autoimmune inflammatory CNS disorders. One of the most extensively studied is myelin oligodendrocyte glycoprotein (MOG), largely used in animal models to induce experimental demyelination ${ }^{4}$. The MOG is a glycoprotein of 218 aminoacids expressed exclusively in the plasmatic membrane of the oligodendrocytes within the CNS. It is a minor compound of the myelin sheath but its localization on the outer surface made it accessible to reactive antibodies. It is belived that its extracellular domain induces cellular and humoral autoimmunity 5 . Antibodies directed against MOG (MOG-IgG) are mostly of the IgG1 subtype and are able to induce cytotoxicity and to fix complement ${ }^{5}$.

The MOG-IgG is observed in several clinical syndromes, such as NMOSD, idiopathic recurrent or bilateral optic neuritis (ON), isolated myelitis, acute demyelinating encephalomyelitis and in pediatric MS. Although, it is not clear if the variable phenotypes that have been linked to MOG-IgG are a result of the technical limitations and lack of a standard

${ }^{1}$ Pontifícia Universidade Católica do Rio Grande do Sul, Faculdade de Medicina, Hospital São Lucas, Serviço de Neurologia, Porto Alegre RS, Brasil;

${ }^{2}$ Instituto do Cérebro do Rio Grande do Sul, Porto Alegre RS, Brasil.

*Both authors contributed equally to this work.

Correspondence: Douglas Kazutoshi Sato; PUCRS; Av. Ipiranga, 6690 / prédio 63; 90610-000 Porto Alegre RS, Brasil; E-mail: douglas.sato@pucrs.br Conflict of interest: There is no conflict of interest to declare.

Received 09 July 2017; Accepted 13 July 2017. 
detection method ${ }^{5}$, or if they indicate certain heterogeneity in the immunological dysfunction that causes the production of these autoantibodies.

Advanced techniques of molecular biology using cellbased assays are more sensitive and specific than those using enzyme-linked immunosorbent assays -ELISA - with linear peptides or western blot using denatured protein. The cellbased assay method is based on transfection of live human cells with human DNA to generate expression of the MOG on the plasmatic membrane. Autoantibodies directed to conformational epitopes are then detected in the patient's sera. The cell-based assay has allowed better characterization of the clinical, radiological and laboratorial profiles of positive patients and the prognostic value of MOG-IgG. Also, it has helped investigate its potential pathogenic effects.

Previous studies in MOG-IgG positive AQP4-Ab negative NMOSD patients have suggested different clinical characteristics when compared with AQP4-Ab positive patients, such as the lack of female predominance, more caudal spinal cord lesions, better recovery from the attacks and a more frequent involvement of optic nerves, with bilateral simultaneous $\mathrm{ON}^{6}$. Other clinical syndromes still lack characterization due to the low number of cases and the need for confirmation in different cohorts.

Considering that MOG-IgG potentially represents a valuable diagnostic and prognostic marker for idiopathic inflammatory CNS inflammatory disorders, we compared the clinical, radiological and laboratorial characteristics of MOG-IgG-positive optic neuritis with MS-associated ON.

\section{METHODS}

We selected 38 patients admitted with acute/subacute ON to our Neuroimmunology Center at São Lucas Hospital of Pontifical Catholic University of Rio Grande do Sul between December 2014 and December 2015. We excluded patients who fulfilled the diagnostic criteria for $\operatorname{NMOSD}^{7}(\mathrm{n}=5)$, patients with $\mathrm{ON}$ with a non-inflammatory cause or associated with systemic diseases (one with sarcoidosis, one with pituitary adenoma and one with psychosomatic symptoms), and patients with insufficient data $(n=2)$. Of the remaining patients, eight fulfilled the diagnostic criteria for MS, according the McDonald criteria of $2010^{8}$ (Figure). Twenty non-MS ON patients were tested for AQP4-IgG using cell-based assays and all patients were negative. All MS-ON and the 20 idiopathic ON (ION) were tested for MOG-IgG.

Patients' sera were used to evaluate the presence of MOG-IgG. Live HEK-293 cells were transfected with a plasmid containing human full-length MOG cDNA, as previously reported $^{6}$, using the transfection agent FUGENE-HD (Promega Corp. Madison, WI, USA). The cells were exposed to patient diluted sera and then to a secondary goat anti-human IgG Fc-specific Dy-488 tagged antibody (Thermo-Fischer,
USA) to avoid cross-reaction with other immunoglobulin classes. The samples were tested at least twice for MOG-IgG at 1:128 dilution and only those considered positive by two different examiners were counted as true positives. The antibody titers were determined by final double dilution.

The clinical, radiological and laboratorial characteristics of the patients were collected by chart review. We compared three groups: MS-ON, ION MOG-IgG positive, and ION MOG-IgG negative.

All data and samples were collected after approval by the Ethics Committee of Pontifical Catholic University of Rio Grande do Sul and all patients were informed and spontaneously consented to participate in a written agreement research form.

\section{RESULTS}

All eight MS-ON patients were negative for MOG-IgG. Of the 20 ION patients, six (30\%) were MOG-IgG positive and 14 (70\%) were negative.

Amongst the MOG-IgG positive group, the titers ranged from 1:256 to 1:4,096, with a median titer of 1:1,024. The MOG-IgG patients were predominantly male (male:female ratio of 2:1). Median age was 47 years (ranging from 20 to 63 years). One patient presented with recurrent $\mathrm{ON}$; the remaining seven patients presented with a single attack. Two patients presented with a T2-hypersignal with gadolinium enhancement of the optic nerve on the orbital MRI. Two patients had unspecific T2/FLAIR hyperintensities in the brain white matter. Regarding treatment, all MOG-IgG positive patients were treated with intravenous methylprednisolone $1 \mathrm{~g}$ per day for 3-5 days. Three patients also received plasma exchange due to partial recovery after IV corticosteroids. Three patients received immunosuppression with azathioprine. The main reasons for the use of azathioprine were recurrence and/or severity (Table 1).

The ION patients with MOG-IgG were older than the MS patients (median 47, ranging from 20 to 69 years). Male predominance was more significant in the MOG-IgG ION group compared to the ON-MS and MOG-IgG negative group. All patients with MS had typical brain lesions compared with the unspecific changes in the MOG-IgG ON patients. None of the ION patients presented with spinal cord lesions during their admission. The MOG-IgG positive patients did not have a family history of systemic autoimmunity. Amongst MOG-IgG ION negative patients, there were family history of psoriasis and rheumatoid arthritis, and amongst MS patients, there were family history of rheumatoid arthritis. There was no difference in the number of ON attacks between the evaluated groups (Table 2).

The ION MOG-IgG positive patients received plasma exchange proportionally more frequently than the ION MOG-IgG negative and the MS patients. Three ION MOG-IgG positive and two MOG-IgG negative patients received long-term immunosuppression with azathioprine. One MOG-IgG negative ION patient was also treated with mycophenolate mofetil (Table 2). 


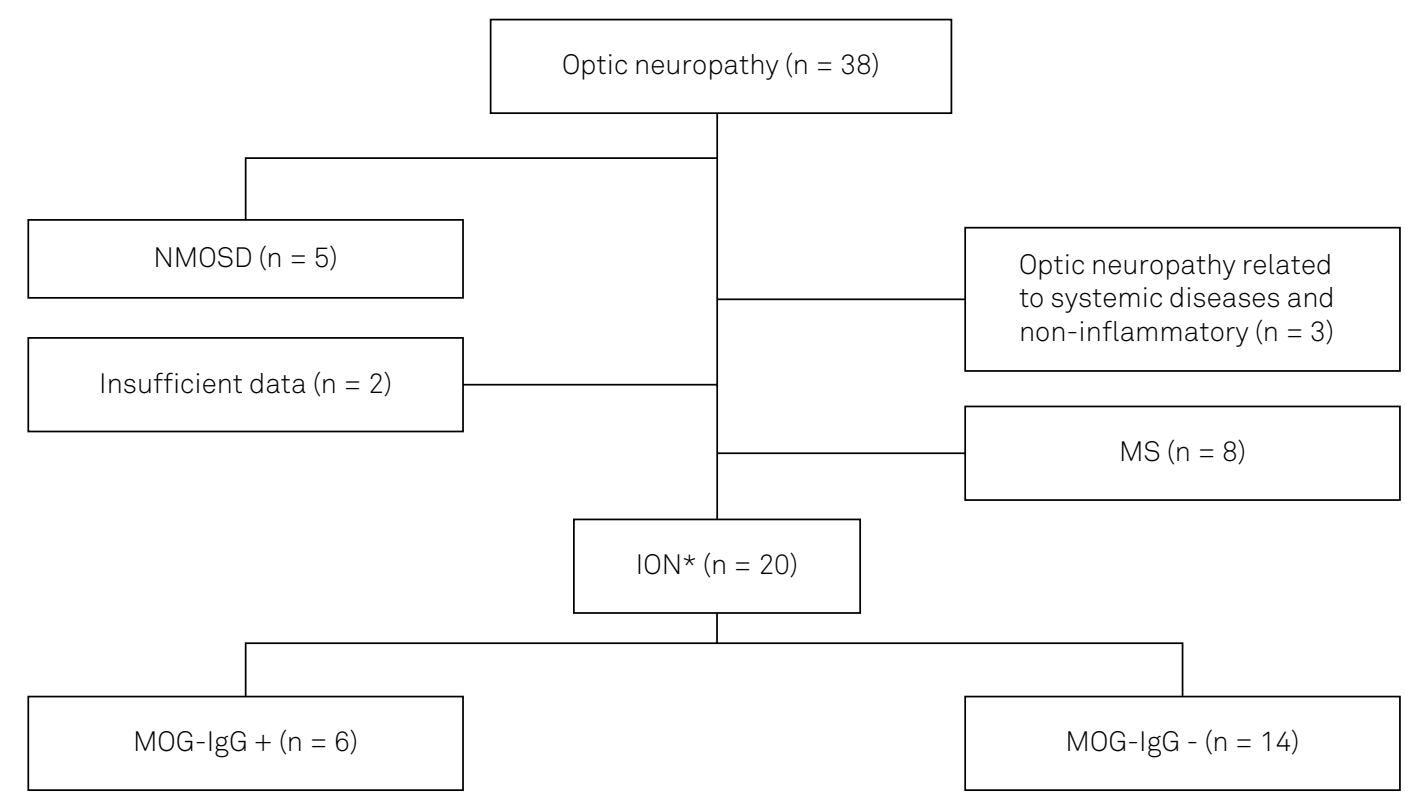

ION: idiopathic optic neuritis; MS: multiple sclerosis; NMOSD: neuromyelitis optica spectrum disorders; MOG-IgG: antibody antimyelin oligodendrocyte glycoprotein; *ION: idiopathic ON (non related to MS, NMOSD, after ruling out noninflammatory and systemic causes).

Figure. Study flowchart.

Table 1. Clinical, radiological and laboratory characteristics of MOG-IgG positive patients.

\begin{tabular}{|c|c|c|c|c|c|c|c|}
\hline Patient & $\begin{array}{l}\text { Gender / } \\
\text { Race }\end{array}$ & $\begin{array}{c}\text { Age at onset } \\
\text { (years) }\end{array}$ & $\begin{array}{l}\text { Number of } \\
\text { ON episodes }\end{array}$ & Lateralization & $\begin{array}{l}\text { MOG-IgG } \\
\text { titers }\end{array}$ & Neuroimaging & Treatment \\
\hline 1 & $F / W$ & 63 & 1 & Bilateral ON & $1: 1,024$ & $\begin{array}{l}\text { Unspecific subcortical } \\
\text { lesions }\end{array}$ & $\begin{array}{c}\text { IVMP } \\
\text { Azathioprine }\end{array}$ \\
\hline 2 & $\mathrm{M} / \mathrm{Mu}$ & 38 & $1 *$ & Bilateral ON & $1: 256$ & Not evaluated & None \\
\hline 3 & $M / W$ & 41 & 1 & Bilateral ON & $1: 1,024$ & Normal & $\begin{array}{l}\text { IVMP + PLEX } \\
\text { Azathioprine }\end{array}$ \\
\hline 4 & $F / W$ & 20 & 1 & Right ON & $1: 4,096$ & $\begin{array}{l}\text { Optic nerve edema with } \\
\text { gadolinium enhancement }\end{array}$ & IVMP + PLEX \\
\hline 5 & $M / W$ & 69 & 2 & $\begin{array}{l}\text { Recurrent ON } \\
\text { Left / Right }\end{array}$ & $1: 1,024$ & $\begin{array}{c}\text { Unspecific white matter T2 } \\
\text { hyperintensities }\end{array}$ & IVMP + PLEX \\
\hline 6 & $M / W$ & 53 & 1 & Bilateral ON & $1: 2,048$ & Optic nerve edema & $\begin{array}{c}\text { IVMP } \\
\text { Azathioprine }\end{array}$ \\
\hline
\end{tabular}

F: female; M: male; W: White; Mu: Mulatto; ON: optic neuritis; MOG: myelin oligodendrocyte glycoprotein; MPIV: intravenous methylprednisolone; PLEX: plasma exchange; ${ }^{1}$ attack: simultaneous $\mathrm{ON}$ and myelitis.

Table 2. Comparison between MOG-IgG positive, MOG-IgG negative and multiple sclerosis patients.

\begin{tabular}{|c|c|c|c|}
\hline Variable & MOG-IgG positive $(n=6)$ & MOG-IgG negative $(n=14)$ & MS-ON $(n=8)$ \\
\hline Age at disease onset, median (min-max) & $47(20-63)$ & $50.5(18-69)$ & $29(23-50)$ \\
\hline$M: F$ & $4: 2$ & 9:5 & $1: 7$ \\
\hline Disease duration, years (min-max) & $2(0.5-6)$ & $1.5(0.1-15)$ & $9.5(1-15)$ \\
\hline Number of $\mathrm{ON}$ attacks, $\mathrm{n}$ (min-max) & $1(1-2)$ & $1.5(1-6)$ & $1(1-2)$ \\
\hline Family history of autoimmunity, \% (n/total) & 0 & $14.3(2 / 14)$ & $12.5(1 / 8)$ \\
\hline Encephalic lesions, \% (n/total) & $33(2 / 6)$ & $21.4(3 / 14)$ & $100(8 / 8)$ \\
\hline Autoantibodies, \% (n/total) & $16.6(1 / 6)$ & $35.7(5 / 14)$ & $12.5(1 / 8)$ \\
\hline \multicolumn{4}{|l|}{ Acute phase treatment } \\
\hline IV methylprednisolone (n/total) & $83.3(5 / 6)$ & $78.6(11 / 14)$ & $75(6 / 8)$ \\
\hline Plasma exchange \% (n/total) & $50(3 / 6)$ & $35.7(5 / 14)$ & $12.5(1 / 8)$ \\
\hline
\end{tabular}

MS: multiple sclerosis; ON: optic neuritis; M: male; F: female; MOG: myelin oligodendocyte glycoprotein. 


\section{DISCUSSION}

This study compared ION with MS-ON patients. All MS patients were negative for MOG-IgG, as reported by other studies. For example, Chalmoukou et al. ${ }^{9}$ tested 42 relapsingremitting MS and primary progressive MS patients and did not find MOG-IgG seropositivity, and Ramanathan et al. ${ }^{10}$ evaluated 76 relapsing-remitting MS, primary progressive MS and secondary progressive MS patients and found only one MOG-IgG positive patient. These findings suggest that MOGIgG could be a biomarker of a demyelinating disease distinct from MS in adults. We might suppose that the initial results that found MOG-IgG positivity amongst MS patients in earlier studies not using cell-based assays were probably due to the lower assay specificity.

As suggested by previous results (Table 3), MOG-IgG positive patients may present with a clinical diagnosis of idiopathic $\mathrm{ON}^{9,11}$ or NMOSD ${ }^{6,10}$. The MOG-IgG patients frequently have recurrent or bilateral $\mathrm{ON}$ and the male predominance contrasts with the female predominance in MS. There is still controversy concerning the age at disease onset. While Nakajima et al. ${ }^{12}$ found younger ages at presentation, this and previous studies with NMOSD MOG-IgG positive patients ${ }^{6}$ suggest an older age when compared with MOG-IgG negative subgroups.

Previous studies pointed to higher frequencies of recurrent ION in MOG-IgG positive patients9. We observed recurrence in only one patient, however, given the transversal design of our study, it is not possible to assume a lower frequency of recurrence in our cohort.

As was previously observed in NMOSD patients, this study did not find significant brain lesions in the ION
MOG-IgG seropositive subgroup. Nevertheless, optic nerves may have particular susceptibility to MOG-IgG autoantibodies given the frequency of their involvement ${ }^{11}$. These findings could represent a clinical scenario suggestive of MOG-IgG positivity and could be used to guide laboratory investigations in clinical practice.

This study has limited capacity to estimate recurrence and long-term outcomes of ION related to MOG-IgG, due to our small sample and study design. However, this study adds important demographic and clinical information in the initial presentation that could indicate positivity to MOG-IgG in ON. Also, it confirms, in the Brazilian population, previous data of other groups.

These preliminary findings need to be confirmed by longterm evaluation of larger groups, as careful investigation of possible pathogenic effects of MOG-IgG and follow up of the antibody titers could be used as prognostic markers. Also, it is necessary to confirm the favorable visual recovery of MOG-IgG positive patients, as previously seen in $\mathrm{ION}^{9,11}$ and NMOSD ${ }^{6,10}$ cohorts.

The use of reliable serologic tests, such as cell-based assays, to guide a detailed evaluation of previouslydescribed inflammatory idiopathic CNS syndromes associated with MOG-IgG will help define the clinical spectrum of this antibody and the best therapeutic approach to manage these patients.

\section{ACKNOWLEDGMENTS}

Authors thank patients and their families for their collaboration in this study.

Table 3. Comparison between this study and previous studies.

\begin{tabular}{|c|c|c|c|}
\hline \multirow{2}{*}{ Study } & Chalmoukou et al. $2015^{10}$ & Nakajima et al $2015^{12}$ & This study \\
\hline & $(n=8)$ & $(n=8)$ & $(n=6)$ \\
\hline Age, years, median (range) & $41(20-46)$ & $31(16-65)$ & $47(20-63)$ \\
\hline Sex M:F & $2: 6$ & $2: 6$ & $4: 2$ \\
\hline Recurrent ON, n (\%) & $5 / 8(62,5 \%)$ & $2 / 8(25 \%)$ & $1 / 6(16.6 \%)$ \\
\hline Bilateral or recurrent ON, n (\%) & $8 / 8(100 \%)$ & $3 / 8(37.5 \%)$ & $5 / 6(83.3 \%)$ \\
\hline Abnormal orbital MRI, n/total (\%) & $2 / 8(25 \%)$ & $7 / 8(87.5 \%)$ & $2 / 6(33.3 \%)$ \\
\hline Abnormal brain MRI, n/total (\%) & 0 & $2 / 8(25 \%)$ & $2 / 6(33.3 \%)$ \\
\hline Presence of spinal cord lesions, n/total (\%) & $1 / 8(12,5 \%)$ & $1 / 8(12.5 \%)$ & 0 \\
\hline MOG-IgG titers (1:x) & $160->640$ & N.A. & $256-4096$ \\
\hline \multicolumn{4}{|l|}{ Treatments, n/total (\%) } \\
\hline IV methylprednisolone & $8 / 8(100 \%)$ & $8 / 8(100 \%)$ & $5 / 6(83.3 \%)$ \\
\hline IV immunoglobulin & $1 / 8(12,5 \%)$ & 0 & 0 \\
\hline Azathioprine & 0 & 0 & $2 / 6(33.3 \%)$ \\
\hline Mycophenolate mofetil & $1 / 8(12,5 \%)$ & 0 & $1 / 6(16.6 \%)$ \\
\hline Plasma exchange & $1 / 8(12,5 \%)$ & $1 / 8(12.5 \%)$ & $3 / 6(50 \%)$ \\
\hline Rituximab & $1 / 8(12,5 \%)$ & 0 & 0 \\
\hline
\end{tabular}




\section{References}

1. Popescu BF, Lucchinetti CF. Pathology of demyelinating diseases. Annu Rev Pathol. 2012;7(1):185-217. https://doi.org/10.1146/annurev-pathol-011811-132443

2. Ferguson B, Matyszak MK, Esiri MM, Perry VH. Axonal damage in acute multiple sclerosis lesions. Brain. 1997;120(Pt 3):393-9. https://doi.org/10.1093/brain/120.3.393

3. Lennon VA, Wingerchuk DM, Kryzer TJ, Pittock SJ, Lucchinetti CF, Fujihara K et al. A serum autoantibody marker of neuromyelitis optica: distinction from multiple sclerosis. Lancet. 2004;364(9451):2106-12. https://doi.org/10.1016/S0140-6736(04)17551-X

4. Mayer MC, Meinl E. Glycoproteins as targets of autoantibodies in CNS inflammation: MOG and more. Ther Adv Neurol Disorder. 2012;5(3):147-59. https://doi.org/10.1177/1756285611433772

5. Reindl M, Di Pauli F, Rostásy K, Berger T. The spectrum of MOG autoantibody-associated demyelinating diseases. Nat Rev Neurol. 2013;9(8):455-61. https://doi.org/10.1038/nrneurol.2013.118

6. Sato DK, Callegaro D, Lana-Peixoto MA, Waters PJ, Jorge FMH, Takahashi T et al. Distinction between MOG antibody-positive and AQP 4 antibody-positive NMO spectrum disorders. Neurology. 2014;82(6):474-81. https://doi.org/10.1212/WNL.0000000000000101
7. Wingerchuk DM, Banwell B, Bennett JL, Cabre P, Carroll W, Chitnis T et al. International consensus diagnostic criteria for neuromyelitis optica spectrum disorders. Neurology. 2015;85(2):177-89. https://doi.org/10.1212/WNL.0000000000001729

8. Polman CH, Reingold SC, Banwell B, Clanet M, Cohen JA, Filippi M et al. Diagnostic criteria for multiple sclerosis: 2010 revisions to the McDonald criteria. Ann Neurol. 2011;69(2):292-302. https://doi.org/10.1002/ana.22366

9. Chalmoukou K, Alexopoulos H, Akrivou S, Stathopoulos P, Reindl M, Dalakas MC. Anti-MOG antibodies are frequently associated with steroid-sensitive recurrent optic neuritis. Neurol Neuroimmunol Neuroinflamm. 2015:2(4):e131. https://doi.org/10.1212/NXI.0000000000000131

10. Ramanathan S, Reddel SW, Henderson A, Parratt JD, Barnett M, Gatt PN et al. Antibodies to myelin oligodendrocyte glycoprotein in bilateral and recurrent optic neuritis. Neurol Neuroimmunol Neuroinflamm. 2014;1(4):e40. https://doi.org/10.1212/NXI.0000000000000040

11. Nakajima H, Motomura M, Tanaka K, Fujikawa A, Nakata R, Maeda Y et al. Antibodies to myelin oligodendrocyte glycoprotein in idiopathic optic neuritis. BMJ Open. 2015;5(4):e007766. https://doi.org/10.1136/bmjopen-2015-007766 